\title{
Evaluation of Distance Education through Blended Learning: Comparisons and Important Factors for the Learning Process
}

\author{
Júlio C. G. Bertolin ${ }^{1}$, Ana Carolina Bertoletti De Marchi ${ }^{2}$ \\ ${ }^{1}$ Graduate Program in Education, University of Passo Fundo, Passo Fundo, Brazil \\ ${ }^{2}$ Graduate Program in Applied Computing, University of Passo Fundo, Passo Fundo, Brazil \\ Email: julio@upf.br, carolina@upf.br
}

Received December $6^{\text {th }}$, 2013; revised January $6^{\text {th }}, 2014$; accepted January $13^{\text {th }}, 2014$

\begin{abstract}
Copyright (c) 2014 Júlio C. G. Bertolin, Ana Carolina Bertoletti De Marchi. This is an open access article distributed under the Creative Commons Attribution License, which permits unrestricted use, distribution, and reproduction in any medium, provided the original work is properly cited. In accordance of the Creative Commons Attribution License all Copyrights (C) 2014 are reserved for SCIRP and the owner of the intellectual property Júlio C. G. Bertolin, Ana Carolina Bertoletti De Marchi. All Copyright (C) 2014 are guarded by law and by SCIRP as a guardian.
\end{abstract}

Evaluation is a complex issue with significant importance for the qualification of institutions and college education programs. In distance education, quality assessment is even more complex and important as the differences in space and time between professors and students have an impact on the learning process. A blended learning environment is one that combines distance education and face-to-face classroom instruction, and whose courses are an ideal environment for comparison with the conventional method. In this respect, this paper conducts an evaluation of blended learning through which students assess some aspects related to the development of courses and to the learning outcomes. The evaluation revealed that, in general, students considered that the face-to-face classroom contact facilitated learning and that the professor's planning and commitment are key factors in distance education.

Keywords: Distance Education; E-Learning; Evaluation Methodologies

\section{Introduction}

Evaluation is a complex and significantly important issue concerning quality assessment tools and projects in institutions and college education programs. Different approaches have been used to assess higher education and quality of education, and distinct conceptions and forms for evaluating education have been employed. In the past two decades, the assessment of higher education has been a matter for vigorous debate, with the participation of professionals and researchers from different areas of knowledge. However, in the context of distance education, studies and works on assessment are still in the process of being developed. In distance education, quality assessment is more complex and more important as the differences in space and time between professors and students have an impact on the learning process.

While some authors and professors call into question whether the quality of distance education is good and whether students can effectively learn from this method, some studies have shown that the quality of this type of education can be as good as or better than face-to-face classroom education. At the same time, distance education has greatly expanded worldwide, both in developed and developing countries.

For instance, in Brazil, the number of distance education students accounted for only $1 \%$ of the total of undergraduate programs in 2004, whereas in 2010, nearly 1 million students represented $15 \%$ of the whole system. In this period, the growth of distance education averaged $65 \%$ p.a. compared to only $5 \%$ of face-to-face education in Brazilian higher education pro- grams. In the United States, studies demonstrate that 3.5 million students attended distance education programs in higher education institutions in 2006. From 2004 to 2009, there was an average increase of $13 \%$ p.a. in the number of enrollments in distance education in the US compared to an average growth of approximately $2 \%$ in the whole system.

Another option between distance education and face-to-face classroom instruction is blended learning, which combines both methods. The Brazilian Ministry of Education, for example, allows up to $20 \%$ of the total hours in a face-to-face classroom environment to be taught in the distance education mode. Within the scope of a course, education is allowed to take place fully or partially in the distance mode, but tests must be taken in a face-to-face environment. Thus, a course under the blended education mode, despite the predominance of face-to-face instruction, is significantly flexible in terms of time and space during the learning process. Such flexibility provides a unique environment for the investigation of distance education quality as the same group of students in the same course, taught by the same professor, is submitted to both methods: distance education and conventional face-to-face education. Consequently, the assessment of distance education quality in the blended education mode is an ideal environment for comparison with the face-to-face classroom method, both in terms of learning process and course outcomes.

In this respect, the present paper seeks to contribute towards quality assessment of distance education using a case report that investigated the students' perception about the best learning method between face-to-face and distance education, in 
addition to factors that were relevant for the development of distance education. The theoretical and methodological background drew upon the concept of quality in education represented by a set of indicators based on the General Systems Theory (Estrada, 1999) which involve aspects of the learning process and of the assessed educational object.

\section{Evaluation Method and Tool}

Given the expansion of and debate on school efficiency, performance or learning of students, several research studies on distance education quality have been undertaken. Among the approaches used to assess this type of education, we have the following: 1) comparison of distance education with face-toface classroom instruction using predefined quality indicators; 2) the use of tools to identify users' perceptions through their answers to questionnaires or devices that store and analyze the duration and frequency of login or accessed pages; 3 ) the comparison with an ideal hypothetical system that contains a set of relevant requirements and functions; and 4) the use of indicators to assess the online learning platform or environment (Valcheva \& Todorova, 2005).

In order to assess distance education through the blended approach, the present study drew upon the concept of quality in education represented by a set of indicators based on the General Systems Theory that involve input, process and outcome aspects and/or indicators of the assessed educational object. According to Estrada (1999), quality of education assessment is expressed by a value judgment about a set of attributes related to "inputs", "process" and "outcomes", or about the relationships between them. UNESCO's Laboratorio Latinoamericano de Evaluación de la Calidad de la Educación also mentions systemic indicators, stating that "the level of quality in education consists basically of the definition of a set of variables that systematically provides a reliable and valid panorama of educational systems that can be used to guide and implement improvement strategies” (UNESCO, 1997).

According to García (2000), the systems of indicators seek to go beyond the mere sum of data by grouping simple or composite indicators as a function of factors and aspects that render them meaningful and provide a significant insight into the status of educational systems. Experiences with the assessment of indicator systems demonstrate that quality in education is a multiple concept that cannot be evaluated by a single aspect and that should include all the key elements of the system or process. Therefore, we may say that it is possible to assess the quality of education by a value judgment based on a set of attributes, aspects or indicators concerning inputs, process and educational outcomes, or the relationships between them.

Hence, in view of the goals of the evaluation study, we assumed that the quality assessment of courses in the blended education model is closely related to the analysis of performance of a set of input, process and outcome indicators. More specifically, to compare students' learning between the face-toface and distance education models, we used three questions about this aspect, as proposed by Bertolin \& De Marchi (2010) as evaluation tool for courses in a blended education environment based on systemic indicators (Table 1). Likewise, questions on the process of the same tool were compared with those about learning outcomes in order to identify more relevant factors and improve students' learning in distance education.

The questionnaires were applied to students of 46 courses
Table 1.

Questions on input, process and outcomes of courses taught in the blended mode.

1) How do you rate the distance education infrastructure (computer learning center, etc.) available for the course?

Input

aspects 3) How do you rate the professor's skills and competencies in the course?

4) How do you rate your computer literacy before the beginning of the course?

5) How do you rate the distribution of classes in the distance education environment organized by the professor in the Moodle platform?

6) How do you rate the teaching material (support material, activities and media) prepared by the professor?

7) How do you rate the interaction between professor and student during the course?

8) How do you rate the follow-up (feedback concerning the activities) given by the professor during the course?

Process 9) How do you rate the technical support provided by the UPF aspects Virtual platform during the course?

10) How do you rate the alternating rounds and adequacy of face-to-face and distance education methods (syllabus and number of hours) in the course?

11) How do you rate the professor's teaching/pedagogical practice in the face-to-face classroom environment?

12) How do you rate your dedication and commitment to distance education classes?

13) How do you rate the level of demand of distance education activities proposed by the professor for the course?

14) How do you rate your learning as far as the syllabus of the face-to-face course is concerned?

15) How do you rate your learning as far as the syllabus of the Outcome distance education course is concerned?

aspects 16) How do you rate the development of your computer skills during the course?

17) How do you rate the development of your autonomy and self-organization during the course?

Note: Source: Bertolin \& De Marchi (2010).

taught in the blended education environment during the second half of year 2011 at a nonprofit university located in southern Brazil. A total of 618 students from different undergraduate programs answered the questionnaire. Class hours accounted for $20 \%, 50 \%$ and $80 \%$ of 358, 137 and 123 evaluated courses, respectively. In each question, the students had to check one of the following options: "very poor” (value 1); "poor” (value 2); "fair” (value 3); "good” (value 4); and "excellent” (value 5).

For the comparison of learning between face-to-face and distance education, we performed some calculations: 1) for the total amount of students taking up courses in the blended mode who considered learning in the face-to-face environment to be better than, equal to or worse than distance education; and 2) for the arithmetic means of the 47 courses in the blended method, which refer to students' perception about learning in the face-to-face and distance education environments (questions 14 and 15).

After that, in order to investigate the most relevant factors for improvement of students' learning in the distance education 
environment (3), we compared the low means obtained for 11 courses with $50 \%$ of classes in the distance mode and $50 \%$ of them in the face-to-face mode in the questions on input and process (questions 1 through 13) and the most significant differences between the means obtained for face-to-face and distance education (question 14 subtracted from question 15).

\section{Calculations and Analyses}

The blended learning approach provides a unique environment for the investigation of distance education quality as the same group of students in the same course, taught by the same professor, is submitted to both methods: distance education and conventional face-to-face education.

In the comparison of respondents' perception about learning in both environments, most answered that learning was better in the face-to-face environment. While $84 \%$ of students found face-to-face education to be better than distance education, only $4 \%$ thought it was the other way around. Slightly over $10 \%$ of 618 respondents considered face-to-face and distance education to be equivalent in terms of quality (Table 2 ).

More specifically in the course with only $20 \%$ of hours in the distance mode, none of the 358 students found distance education to be better than face-to-face education. In those courses in which half of the classes were taught in a face-to-face classroom environment and the remaining half given in the distance mode, i.e., when we probably had the best condition for comparison between the methods, $94 \%$ of the students considered face-to-face education to be better.

With respect to the 47 courses taught in the blended method, only three $(6 \%)$ indicated that learning in the distance mode was better than in the face-to-face environment. In another six courses (13\%), the learning quality of face-to-face and distance education was equivalent. In the remaining 38 courses, learning in the face-to-face environment was found to be better. Therefore, it is beyond doubt that most students who took the same course, taught by the same professor, within the same term, under the blended approach, considered face-to-face education to be better than distance education.

According to the logic of indicators based on the General Systems Theory, good inputs and good processes yield good results. Likewise, poor inputs and poor processes yield poor results. As to the courses taken in the blended mode, the mean results (overall means of 3.9) were consistent with those of the inputs (overall means of 4.0) and of the processes (overall means of 3.8).

Table 2.

Comparison of students' perception about learning in the face-to-face and distance education environments-expressed in numbers and percentage.

\begin{tabular}{ccccccccc}
\hline & $\begin{array}{c}20 \% \\
\mathrm{DE}\end{array}$ & $\%$ & $\begin{array}{c}50 \% \\
\mathrm{DE}\end{array}$ & $\%$ & $\begin{array}{c}80 \% \\
\mathrm{DE}\end{array}$ & $\%$ & Total & $\%$ \\
\hline $\begin{array}{c}\text { FFE better } \\
\text { than DE }\end{array}$ & 316 & 88 & 129 & 94 & 75 & 61 & 520 & 84 \\
$\begin{array}{c}\text { DE as good } \\
\text { as FFE }\end{array}$ & 42 & 12 & 3 & 2 & 28 & 23 & 73 & 12 \\
$\begin{array}{c}\text { DE better } \\
\text { than FFE }\end{array}$ & 0 & 0 & 5 & 4 & 20 & 16 & 25 & 4 \\
\hline
\end{tabular}

Note: Source: Data collected by the authors. FFE = face-to-face education; DE = distance education.
In general, the assessments of input aspects (infrastructure, virtual learning environment, professors' and students' skills) and of processes (planning of dynamics, interaction, support, alternation, etc.) were similar to those of the outcomes (learning and skill development). However, the means for question 15 was not always consistent with the assessment of inputs and processes (Table 3). More specifically, the statistical significance of courses 139229, 139230 and 139232 was below the mean obtained for the distance education environment. Thus, the comparison of the means obtained for the questions on input and process with the largest differences between the means for the questions in the distance and face-to-face education helped determine the most influential aspects that hinder distance education.

By subtracting the means obtained by the courses taught in the face-to-face mode by the means of those in the distance mode, courses 139229 and 139230 yielded significantly different results (Table 4). These courses showed much poorer learning rates in the distance mode than in the face-to-face environment. Hence, a more accurate analysis of inputs and processes of these two courses can indicate aspects that have a negative impact on learning in the distance education environment.

In a more careful interpretation of the assessment of these two courses with the worst results for distance education, we can initially perceive that no question in the input domain was assessed in a significantly different fashion from the mean of all courses (Table 5). However, the questions on professors' teaching planning and commitment, in the process domain, yielded significantly lower means in courses 139,229 and 139,230 than the overall means of all courses.

This way, the teaching material prepared by the professor (question 6), the interaction between professor and student (question 7) and the alternating rounds and adequacy between face-to-face and distance education (question 10) were more

Table 3.

Means of input, process and outcome aspects of courses in the blended learning environment.

\begin{tabular}{ccccc}
\hline Courses & Inputs & Process & 15 & Outcomes \\
\hline 139,407 & 4.4 & 4.3 & 4.1 & 4.3 \\
139,215 & 3.9 & 3.7 & 3.6 & 3.9 \\
139,229 & 3.7 & 3.5 & 2.6 & 3.5 \\
139,230 & 3.7 & 3.3 & 2.3 & 3.3 \\
139,232 & 3.8 & 3.6 & 2.8 & 3.5 \\
139,249 & 3.9 & 4.1 & 3.2 & 3.9 \\
139,383 & 4.2 & 4.2 & 3.9 & 4.0 \\
139,387 & 4.1 & 3.8 & 4.3 & 4.2 \\
140,806 & 3.9 & 3.7 & 3.5 & 3.9 \\
140,898 & 3.7 & 3.4 & 3.6 & 3.9 \\
141,615 & 4.1 & 4.2 & 3.9 & 4.2 \\
Mean & 4.0 & 3.8 & 3.4 & 3.9 \\
\hline
\end{tabular}

Note: Source: Data collected by the authors. 
relevant for distance education in the assessment of the courses taught in the blended mode.

Table 4.

Differences in learning in the face-to-face and distance education courses taught in the blended mode (50\% DE and 50\% FFE).

\begin{tabular}{|c|c|c|c|}
\hline Course & Question 14 & Question 15 & Difference \\
\hline 139,407 & 4.3 & 4.1 & 0.2 \\
\hline 139,215 & 3.8 & 3.6 & 0.2 \\
\hline 139,229 & 4.1 & 2.6 & 1.5 \\
\hline 139,230 & 3.8 & 2.3 & 1.6 \\
\hline 139,232 & 3.7 & 2.8 & 0.8 \\
\hline 139,249 & 4.0 & 3.2 & 0.8 \\
\hline 139,383 & 4.1 & 3.9 & 0.2 \\
\hline 139,387 & 4.1 & 4.3 & -0.1 \\
\hline 140,806 & 4.1 & 3.5 & 0.5 \\
\hline 140,898 & 4.0 & 3.6 & 0.4 \\
\hline 141,615 & 4.4 & 3.9 & 0.5 \\
\hline Mean & 4.0 & 3.4 & 0.6 \\
\hline
\end{tabular}

Note: $\mathrm{DE}$ = distance education; FFE = face-to-face education.

\section{Conclusion}

The courses in the blended mode corroborate the unique environment for the investigation into distance education quality given that the same group of students attending the same course taught by the same professor is submitted to alternating rounds of distance and face-to-face education. Consequently, the assessment of distance education quality in the blended mode is ideal for comparisons with the conventional method, both in terms of process and outcomes.

The assessment carried out here compared the perception of more than 600 students in almost 50 courses taught in the blended mode. This procedure demonstrated that, by and large, students find it easier to learn in a face-to-face environment. Nonetheless, in some courses, the difference in perception about learning between the face-to-face and distance education methods was very large, calling into question some factors that could be related to learning difficulties in the distance education mode.

By investigating the factors in the input and process domains that had a greater impact on the comparison of students' learning in the different teaching methods, our assessment showed that the questions on professors' planning and commitment, in the process domain, are relevant for learning in the distance education environment. The negative assessment of the teaching material prepared by the professor, of the interaction between professor and student and of the alternating rounds and adequacy of face-to-face and distance education methods, revealed that these process aspects had a negative impact on distance education.

Therefore, it is plausible to say that, in the context of distance education, a well-planned course and an appropriate

Table 5.

Assessment of questions on input and process in the blended mode (50\% DE and 50\% FFE).

\begin{tabular}{|c|c|c|c|c|c|c|c|c|c|c|c|c|c|c|c|c|}
\hline \multirow{2}{*}{ Course } & \multicolumn{5}{|c|}{ Inputs } & \multicolumn{10}{|c|}{ Process } & \multirow{2}{*}{$\frac{\text { Diff }}{14-15}$} \\
\hline & 1 & 2 & 3 & 4 & Mean & 5 & 6 & 7 & 8 & 9 & 10 & 11 & 12 & 13 & Mean & \\
\hline 139,407 & 4.3 & 4.3 & 4.5 & 4.3 & 4.4 & 4.4 & 4.2 & 4.3 & 4.5 & 4.4 & 3.9 & 4.2 & 4.1 & 4.3 & 4.3 & 0.2 \\
\hline 139,215 & 4.0 & 3.6 & 3.9 & 4.2 & 3.9 & 3.5 & 3.6 & 3.7 & 3.5 & 3.5 & 3.6 & 4.0 & 3.8 & 3.7 & 3.7 & 0.2 \\
\hline 139,229 & 3.6 & 3.4 & 3.6 & 4.3 & 3.7 & 3.4 & 3.6 & 3.1 & 3.3 & 3.8 & 3.1 & 3.8 & 3.5 & 3.6 & 3.5 & 1.5 \\
\hline 139,230 & 3.5 & 3.6 & 3.6 & 4.0 & 3.7 & 3.4 & 3.3 & 2.9 & 3.3 & 3.8 & 2.8 & 3.5 & 3.3 & 3.8 & 3.3 & 1.6 \\
\hline 139,232 & 3.5 & 3.9 & 3.9 & 4.1 & 3.8 & 3.4 & 3.7 & 3.5 & 3.6 & 3.9 & 3.8 & 3.5 & 3.3 & 3.3 & 3.6 & 0.8 \\
\hline 139,249 & 4.0 & 3.4 & 4.2 & 4.0 & 3.9 & 4.0 & 4.4 & 4.2 & 3.8 & 4.0 & 4.0 & 4.4 & 3.8 & 4.0 & 4.1 & 0.8 \\
\hline 139,383 & 4.0 & 3.9 & 4.4 & 4.5 & 4.2 & 4.0 & 4.4 & 4.2 & 4.2 & 4.2 & 4.2 & 4.3 & 3.8 & 4.1 & 4.2 & 0.2 \\
\hline 139,387 & 4.0 & 3.9 & 4.0 & 4.6 & 4.1 & 3.4 & 3.9 & 4.1 & 3.6 & 3.7 & 3.7 & 4.1 & 3.6 & 4.1 & 3.8 & -0.1 \\
\hline 140,806 & 4.1 & 3.6 & 4.0 & 4.1 & 3.9 & 3.7 & 3.5 & 3.6 & 3.6 & 3.8 & 3.6 & 4.1 & 3.9 & 3.5 & 3.7 & 0.5 \\
\hline 140,898 & 3.4 & 3.6 & 3.6 & 4.2 & 3.7 & 3.6 & 4.0 & 3.4 & 3.2 & 3.4 & 3.0 & 3.4 & 3.4 & 3.0 & 3.4 & 0.4 \\
\hline 141,615 & 4.0 & 3.9 & 4.8 & 3.9 & 4.1 & 4.0 & 4.1 & 4.6 & 4.4 & 4.1 & 4.0 & 4.7 & 4.0 & 4.1 & 4.2 & 0.5 \\
\hline Mean & 3.9 & 3.7 & 4.0 & 4.2 & 4.0 & 3.7 & 3.9 & 3.8 & 3.7 & 3.9 & 3.6 & 4.0 & 3.7 & 3.8 & 3.8 & 0.6 \\
\hline
\end{tabular}

Note: Source: Data collected by the authors. DE = distance education; FFE = face-to-face education. 
professor-student interaction are relevant factors for the improvement of students' learning.

\section{REFERENCES}

Bertolin, J. C. G., \& De Marchi, A. C. B. (2010). Instrumentos para avaliar disciplinas da modalidade semipresencial: Uma proposta baseada em sistemas de indicadores. Avaliação (UNICAMP), 15, 1-10.

Estrada, L. R. G. (1999). Hacia un modelo de evaluación de la calidad de instituciones de educación superior. Revista Iberoamericana de Educación, 21, 93-103.
García, M. G. (2000). Evaluación y calidad de los sistemas educativos. In: T. G. Ramírez (Ed.), Evaluación y gestión de la calidad educativa (pp. 227-268). Málaga: Ediciones Aljibe.

United Nations Educational, Scientific and Cultural Organization (UNESCO) (1997). Marco conceptual. Documentos-Laboratorio Latinoamericano de Evaluación de la calidad de la educación. Santiago de Chile: Orealc.

Valcheva, D., \& Todorova, M. (2005). Defining a system of indicators for evaluation the effectiveness of e-learning. In: International Conference on Computer Systems and Technologies-CompSysTech, Varna, 16-17 June 2005, 14-1-14-5. 